\title{
Epidemiology and Risk Factors of Pelvic Inflammatory Disease.
}

\author{
Bandana Pandey ${ }^{1}$.
}

${ }^{1}$ Department of Emergency,Norvic International Hospital, Kathmandu.

\begin{abstract}
Introduction: Knowledge of pelvic inflammatory disease and its epidemiology is essential to understand reproductive morbidity in women. This paperestimates the level of association between demographic factors and pelvic inflammatory disease in women in their reproductive age.

Methods: A descriptive study done in Humla, Kritipur and Baudha by organizing a health camp. Women of reproductive age group and who have lower abdominal pain, pervaginal discharge, fever, and dysparunia were included in the study after taking informed verbal consent from the patient.Patients who have lower abdominal pain and pervaginal discharge were diagnosed as pelvic inflammatory disease.
\end{abstract}

Results: Diagnoses of pelvic inflammatory disease were made in $30 \%$ of attendances amongst women agedbetween 16 to 48. Increased risk of pelvic inflammatory disease was associated with smoking $(P<0.0001)$, age groups $31-40 \mathrm{yrs}(44.6 \%)$,in rural areas $(45 \%)$ and people who are illiterate $(P<0.0001)$. Among 400 , $383(95 \%)$ were reported ever using a modern contraceptive.

Conclusions: The prevalence of pelvic inflammatory diseasewas 30\% in reproductive age group and was significantly associated with smoking.

Keywords: epidemiology; pelvic inflammatory disease; risk factors.

\section{INTRODUCTION}

Pelvic inflammatory disease, the clinical syndrome associated with genital tract infection, is a major health burden in women of reproductive age ${ }^{1}$. Reproductive age group in female is defined as the age between 15 Years to 49 Years $^{2}$. It can cause ectopic pregnancy, tube related infertility and chronic abdominal pain, which is associated with an increased risk of hysterectomy ${ }^{3}$. Little is known of pelvic inflammatory disease (PID) epidemiology in Nepal. Though few studies suggest that $24-32 \%$ women in India 4,5 and $8 \%$ in Pakistan suffer from PID, but we do not have adequate information on magnitude, distribution and determinants of PID and other gynecological morbidities in developing countries $^{6}$.The burden of disease and risk factors associated with PID are poorly understood but need to be investigated to inform public health action and clinical practice $^{7-10}$. This paper aims to critically review current knowledge of PID epidemiology and explore the epidemiological research needed to provide an evidence base for PID public health intervention.

Organising Health camp is an important focus for the diagnosis and treatment of PID. If intervention and surveillance are to be undertaken effectively, more has to be known about the epidemiology of this important public health problem.
Correspondence:

Bandana Pandey

Department of EmergencyNorvic International Hospital

Email: bandana_pb@yahoo.com 


\section{METHODS}

It was a descriptive study done in Humla,Kritipur and Baudha by organizing a health camp.Performa was filledfor each person included in the analysis. Women of reproductive age group and who have lower abdominal pain, pervaginal discharge, fever, and dysparunia were included in the study after taking informed verbal consent from the patient. Patients who have lower abdominal pain and pervaginal discharge were diagnosed as pelvic inflammatory disease. Their demography, behavior, education, parity, use of contraception, age of menarchewere studied.

SPSS version 17 was utilized for analysis of data. Chi square test was used and $\mathrm{P}$ value $<0.005$ were taken significant.

\section{RESULTS}

Total 400 patients were enrolled in the study, 200 were from northest part of midwestern region (humla), 100 from suburban central region (Kirtipur) and 100 from urban region (Baudha). Age ranges from 16 to 48 years. Most people (95\%) were found to use modern method of contraception and half of them preferred injectables. Pelvic inflammatory disease was common in Humla(rural area). $40 \%$ of the patients had PID

PID was more common between the age group of 3140 yrs. Among 400 patients 63\% (251) were smokers (Figure1).

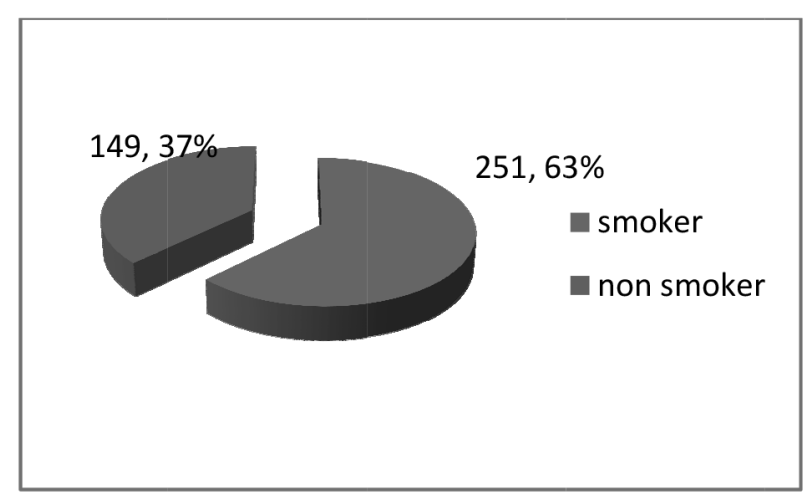

Figure 1.Smoking

Discharge was one of the important symptoms of PID. One hundred twenty one patients (30\%) out of 400 had per vaginal discharge and they were considered having PID.

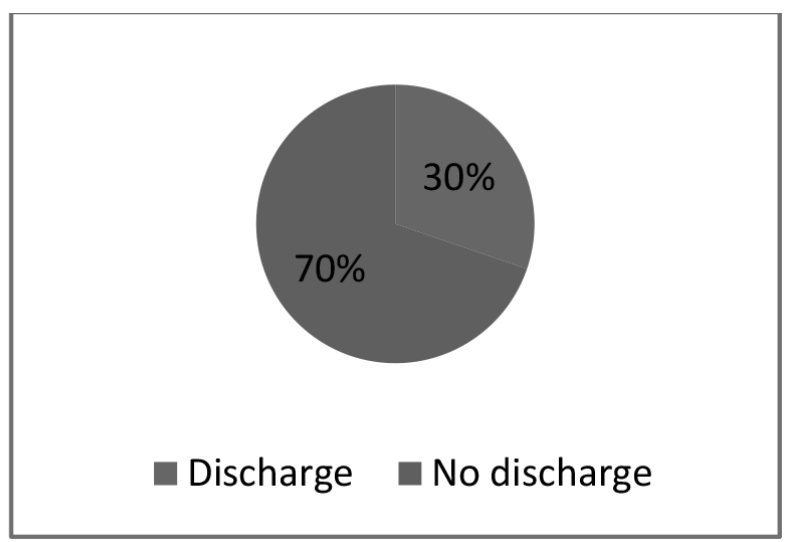

Figure 2. Per vaginal Discharge

Among the patients who had pelvic inflammatory disease, common method of contraception was Inj. Depoprovera, which was used by $51.2 \%$ of population under study. Cupper $\mathrm{T}$ was the second common contraceptive method used which is $24.8 \%$ (table 1 ).

Table 1.Methods of contraception

\begin{tabular}{|l|l|l|}
\hline Methods of contraceptio & Frequency & Percent \\
\hline $\mathrm{Cu} \mathrm{T}$ & 30 & 24.8 \\
\hline OCP & 7 & 5.8 \\
\hline Nor plant & 11 & 9.1 \\
\hline Injdepo & 62 & 51.2 \\
\hline Permanent & 5 & 4.1 \\
\hline None & 6 & 5.0 \\
\hline Total & 121 & 100.0 \\
\hline
\end{tabular}

Majority of patients were smoker in PID group and the difference was statistically significant when compared to non smoker group (Table 2).

Table 2.Relation between smoking habits with PID

\begin{tabular}{|l|l|l|l|l|}
\hline \multirow{2}{*}{ Smoking Habit } & \multicolumn{2}{|l|}{ PID } & Total & \multirow{2}{*}{ P Value } \\
\cline { 2 - 5 } & yes & no & & \\
\hline Smoker & 112 & 139 & 251 & 0.001 \\
\hline Non smoker & 9 & 140 & 149 & \\
\hline
\end{tabular}

\section{DISCUSSION}

Diagnosing PID is challenging because the infection may be localized in one or more of a variety of locations; the symptoms can range from absent, subtle to severe; results of microbiologic assessment often are not readily available; and more accurate diagnostic modalities are invasive, costly, or not easily accessible3. Risk factors for PID include the presence 
of a sexually transmitted infection, a previous episode of PID, sexual intercourse at an early age, high number of sexual partners, and alcohol use. ${ }^{11}$ In addition, several risk factors have been identified for urban adolescents: older sex partners (who may be more sexually experienced and thus more likely to have and spread sexually transmitted infections $)^{7}$. In this study $89 \%$ population were multipara and $29 \%$ among them had PID.

Cigarette smoking has been associated with increased risk of PID ${ }^{12,13}$. Smoking is thought to either compromise the immune response to infection or the activity of oestrogen ${ }^{14,15}$. It is also likely that smoking reflects poor health seeking behavior in lower socioeconomic groups.In this study also there is strong association between smoking and pelvic inflammatory disease $(P<0.001)$.

Despite the development of new diagnostic aids, pelvic inflammatory disease (PID) is still poorly recognized and managed. In 1990, J. Pearce stated: "PID is a sexually transmitted disease with potentially serious squeal usually managed breakthroughs have taken place since that time in the management of PID ${ }^{16,17}$. Last decades have seen an explosion of information on PID based on progress in microbiology,immunology, epidemiology, experimental animal models, and social and behavioral sciences. Despite this, diagnosis remains problematic, and still no rapid simple tests are available to improve the accuracy of clinical diagnosis ${ }^{18,19}$.

The problems associated with PID surveillance stem from the fact that a cheap, simple, and accurate diagnostic test does not exist.8No single infection causes PID and no signs and symptoms are pathgnomonic of the disease. These problems of case definition and diagnostic accuracy are compounded by the inaccessibility of the female upper genital tract to routine, large scale diagnostic methods. Consequently it is difficult to formulate a diagnostic "gold standard." PID surveillance data are also influenced by variations in case definitions (particularly between clinical settings), changes in disease chronicity associated with clinically mild chlamydial infection, variations in health seeking behaviour, and the increased management of PID in outpatient settings ${ }^{20,21}$.

The burden of PID among women, measured in terms of disability adjusted life years, was also higher than the burden of disease associated with HIV among men. However, although PID is not associated with high mortality, it is associated with high morbidity ${ }^{22}$. The absence of validation studies and an explanation of how these data were derived make interpretation difficult. Nevertheless, the data indicate that PID is responsible for a considerable disease burden and represents an important healthcare issue .

The WHO recommends that all sexually active women with lower abdominal pain should be evaluated for the presence of PID; in addition, bimanual and abdominal examinations should be carried out on all women with a presumptive STI, because some women with PID will not experience lower abdominal pain ${ }^{23}$.Syndromic diagnosis may raise diagnostic sensitivity and lead to earlier therapy. On the other hand, it may lead to unnecessary antimicrobial therapies due to its low specificity ${ }^{24}$

Poverty predispose women to infection and limited access to health services utilization increase their risk of RTIs ${ }^{25}$. Hygienic practices and RTIs are negatively associated with each other ${ }^{26}$. People from Humla $(60 \%)$ were mostly affected from pelvic inflammatory disease than boudha (10\%) and kritipur(20\%).

There are three approaches to effective disease control: education and behavioral change, screening for asymptomatic disease, and diagnosis and treatment of symptomatic disease. Behavioural change such as the increased use of barrier contraception and delayed sexual debut in response to HIV and STI health campaigns has been documented in European countries and some have been associated with reduced incidence of symptomatic PID $^{27-29}$.

In the United Kingdom secondary prevention i.e., diagnosis and treatment of asymptomatic genital chlamydial infection, has been successful in reducing both the prevalence of genital chlamydial infection and associated PID. The only randomized controlled trial that has looked at the effectiveness of chlamydial screening indicated that decreases in the prevalence of genital chlamydial infection brought about reductions in PID prevalence ${ }^{29}$.

\section{CONCLUSIONS}

PID was more common in far western region Humal may be due to unawareness of the hygiene,illiteracy. Risk factors for PID were smoking,multiparity,and in the age group between 31-40 yrs. 


\section{REFERENCES}

1. Bang RA, Bang AT, Baitule M, et al. High prevalence of gynecological diseases in rural Indian women. Lancel.1989; $85-88$.

2. Abhay B. Why women hide them, rural women's viewpoint on reproductive tract infections. Haushi-a journal about women and society, New Delhi; 1992.69, pp.27-30.

3. Bhatia JC, Cleland J. Self reported symptoms of gynecological morbidity and their treatment in South India. Stud Fain Plan 1995; 26: 203-16. http://dx.doi.org/10.2307/2137846.

4. Simms I, Hughes G, Catchpole M. Screening for Chlamydia trachomatis. BMJ 1998;317:680-1. http://dx.doi.org/10.1136/ bmj.317.7159.680a.

5. Buchan H, Vessey M, Goldacre M, Fairweather J. Morbidity following pelvic inflammatory disease: a record linkage study. Br J ObstetGynaecol1993;100:558 62 .

6. World Bank. World development report 1993. Investing in health. World development indicators. New York: Oxford University Press, 1993.

7. DB, Kassler WJ, Irwin KL, Rabiee L. Direct medical cost of pelvic inflammatory disease and its sequelae: decreasing, but still substantial. Obstet Gynecol. 2000;95:397-402. Blake DR, Fletcher K, Joshi N, Emans SJ. Identification of symptoms that indicate a pelvic examination is necessary to exclude PID in adolescent women. J PediatrAdolesc Gynecol. $2003 ; 16: 25-30$.

8. Blake DR, Fletcher K, Joshi N, Emans SJ. Identification of symptoms that indicate a pelvic examination is necessary to exclude PID in adolescent women. J PediatrAdolesc Gynecol. 2003; 16:25-30.http://dx.doi.org/10.1016/S1083$\underline{3188(02) 00207-3}$

9. Peipert JF, Ness RB, Blume J, Soper DE, Holley R, Randall $\mathrm{H}$, et al. Pelvic Inflammatory Disease Evaluation and Clinical Health Study Investigators Clinical predictors of endometritis in women with symptoms and signs of pelvic inflammatory disease. Am J Obstet Gynecol.

10. Suss AL, Homel $\mathrm{P}$, Hammerschlag $\mathrm{M}$, Bromberg $\mathrm{K}$. Risk factors for pelvic inflammatory disease in inner city adolescents. Sex Transm Dis. 2000;27:289-91.http://dx.doi. org/10.1097/00007435-200005000-00010.

11. Marchbanks P, Lee N, Petersen H. Cigarette smoking as a risk factor for pelvic inflammatory disease. Am J ObstetGynecol 1990;162:639-44.http://dx.doi.org/10.1016/00029378(90)90973-B.

12. Scholes D, Daling J, Stergachis A. Current cigarette smoking and risk of acute pelvic inflammatory disease. Am J Public Health 1992;82:1352-5.http://dx.doi.org/10.2105/ AJPH.82.10.1352.

13. Hersey P, Prendergast D, Edwards A. Effects of cigarette smoking on the immune system: follow-up studies in normal subjects after cessation of smoking. Med J Aust 1983;2:4259.

14. Pasley J, Rank R, Hough AJ. Effects of various doses of estradiol on chlamydia genital infection in ovariectomized guinea pigs. Sex Transm Dis 1985;12:8-13.http://dx.doi. org/10.1097/00007435-198501000-00003. http://dx.doi. org/10.1097/00007435-198507000-00012.

15. Simms I, Stephenson JM. Pelvic inflammatory disease epidemiology: what do we know and what do we need to know? Sex TransmInf 2000;76:80-87.http://dx.doi. org/10.1136/sti.76.2.80

16. Simms I, Eastick K, Mallinson H, Thomas K, Gokhale R, Hay P, Herring A, Rogers PA. Association between Mycoplasma genitalium, Chlamydia trachomatis, and pelvic inflammatory disease. Sex TransmInf 2003;79:154-156.http://dx.doi. org/10.1136/sti.79.2.154

17. Munday PE. Pelvic inflammatory disease - an evidence-based approach to diagnosis. J Infect 2000;40:31-41.http://dx.doi. org/10.1053/jinf.1999.0609

18. Munday PE. Clinical aspects of pelvic inflammatory disease. Hum Reprod 1997;12(Suppl):121-126.

19. Howard M, Doherty J, Zimic-Vincentic M, et al. An epidemiologic study of a decrease in hospitalizations for pelvic inflammatory disease (PID) in two Canadian cities (1985-1995). Ninth International Symposium on Human Chlamydial Infection, Napa Valley, USA, 1998.

20. Kamwendo F, Forslin L, Bodin L, et al. Decreasing incidences of gonorrhoea and chlamydia associated acute pelvic inflammatory disease. Sex Transm Dis 1996;23:384-91. http://dx.doi.org/10.1097/00007435-199609000-00007

21. OPCS. Mortality statistics, cause: England and Wales, 1992. London: HMSO, 1992.

22. World Health Organization. Guidelines for the management of sexually transmitted infections: Lower abdominal pain 2002, pp. 26-29.

23. Dallabetta GA, Gerbase AC, Holmes KK. Problems, solutions and challenges in syndromic management of sexually transmitted diseases. Sex Transm Dis 1998;74(suppl 1):1-11.

24. Dyson T and Crook N (eds). lndias demography assays on the contemporary population. South Asia Publishers, New Delhi, 1984; pp. 1-10.

25. Younis.N, Khattab.1-1, Zurayk.H, et al. A community study of gynecological and related morbidities in rural Egypt. Stud. Fain. Plan. 1993; 24:175-86.

26. Wølner-Hanssen P, Eschenbach D, Paavonen J. Decreased risk of symptomatic chlamydial pelvic inflammatory disease associated with oral contraception use. JAMA 1990; 263:549.http://dx.doi.org/10.1001/jama.1990.03440010052029. 
http://dx.doi.org/10.1001/jama.263.1.54

27. Coutinho R, Rijsdijk A, van den Hoek J. Decreasing incidence of PID in Amsterdam. Genitourin Med 1992;68:353-5.http:// dx.doi.org/10.1136/sti.68.6.353

28. Egger M, Low N, Smith G, et al. Screening for chlamydia infections and the risk of ectopic pregnancy in a county in
Sweden: ecological analysis. BMJ 1998; 316:1776-80.http:// dx.doi.org/10.1136/bmj.316.7147.1776

29. Scholes D, Stergachis A, Heidrich F, et al. Prevention of pelvic inflammatory disease by screening for cervical chlamydial infection. N Engl J Med 1996; 334:1362-6.http://dx.doi. org/10.1056/NEJM199605233342103 